\title{
British Forces Germany Health Service - Satisfaction Surveys of Patients during 1996 and 1997 in One Geographical Location
}

\author{
Lt Col AJ Leach \\ MB,ChB,MSc(Med),MRCGP,DRCOG,DFFP,RAMC \\ Regional Clinical Director Rhine
}

Medical Centre, Rhine Area Support Unit, British Forces Post Office 40

SUMMARY: The Health Service in British Forces Germany has been subject to considerable change over the last two years. This study shows that the level of satisfaction with the Primary and Community Services in one area has remained consistently high over a twelve month period, even given the large number of changes that have been made to the working practices within the medical centres. This study also reports the fact that nearly $85 \%$ of patients who had attended a German hospital were satisfied with the service that had been provided.

\section{Introduction}

The British Forces Health Service in Germany has undergone considerable change over the last year. Following a successful bid by the Health Alliance (a consortium of the Defence Medical Services, the Soldiers', Sailors' and Airmen's Families Association, Guy's and St Thomas' Hospital Trust and the West Lambeth Community Trust) for the contract to supply health services to the British Forces in Germany, two British Military Hospitals have been closed and the services transferred to local Designated German Provider Hospitals. In addition the primary and community services have been subject to a new management structure and many different working practices, many as a consequence of the changes at Secondary Healthcare. Full details of the process are given elsewhere (1).

The Invitation to Tender for the Health Service Market Test has a requirement for the surveying of patient satisfaction across all elements of the service. In order to meet this requirement, the Rheindahlen Medical Centre undertook patient satisfaction surveys from 1 Jul 96 until 8 Jul 96 and from 16 June 97 until 23 June 97. This study gives information on the methodology and principal results of the surveys, specifically outlining the similarities and differences in result between the two years.

\section{Background}

The Rheindahlen Medical Centre is a large military Practice (population 7,700), open 24 hours a day as "Primary Care Centre". In addition to the services provided on site, such as general practitioner, practice nurse, health visiting, community midwifery and social work, it has a responsibility to provide community physiotherapy, paediatrics and speech and language therapy. These latter disciplines are located at the former RAF Hospital Wegberg. The Rheindahlen Practice is an unusual Military Practice having a large Civil Service and Retired Officer population - it has a morbidity and mortality more akin to an NHS Practice albeit that there are few resident very elderly patients. As examples, registered with the Practice are 15 patients with diabetes mellitus, 37 with malignant neoplasms and 18 with ischaemic heart disease.

During the period of the study the RAF Hospital at Wegberg closed to all in-patient activity (except psychiatry) with the services being provided at the local German hospitals at Viersen and Dülken. Specialities were transferred across individually during the spring and summer of 1996. For example during July 1996 Paediatrics, Obstetrics and Gynaecology had transferred to Viersen, whereas the Surgical and Medical specialities remained at Wegberg. By the end of September 1996, al in-patient activity had ceased at Wegberg, with the exception of psychiatry.

In addition to the changes to Secondary Care, a unifiec management structure for all the primary and community disciplines with a Regional Clinical Director (seniorô general practitioner) and Regional General Manager was implemented. Express responsibility for all disciplines were given to these individuals across a geographical region. For example in the Rhine Region this meant responsibility for four general practices and the remaining community services based at Wegberg which served a population of approximately 12,000 . Other changes to the community services included an increase in community midwifery, psychiatric nursing and pharmacy, and the necessary analysis and adjustment of many internal working practices as the use of the German hospitals was increased. In addition at the same time a large information technology strategy (2) and the Kings Fund Organisational Audit Programme were implemented across the Region.

\section{Methods}

The requirement for conducting a patient satisfaction survey was discussed in the Spring of 1996 at several doctors' and Practice meetings, to try and allay fears and produce commitment. A Medline search was conducted for previous work on patient satisfaction, but many of the studies were either conducted in inappropriate settings such as Accident and Emergency Departments or alternatively either were not suitable for a multidisciplinary survey or to application in Germany $(3,4,5,6)$. On this basis the questionnaire was designed within the Practice using the format that had been trialled 
by the author whilst in Berlin three years previously. The draft questionnaire was circulated to all team members for comments upon understandability and suggestions on other aspects that needed to be covered. Similarly ten random patients were asked to view the questionnaire for their comments.

Core parameters universally felt to be of importance were the service provided by Reception, the amount of time given to the patient, the explanation of the problem, the attitude of the health care professional, how well the health care professional listened to the patient's problem, the service provided by dispensary (if used) and an overall satisfaction level. In addition data were gathered on the age and sex of the patient and whether the patient was seen in or out of hours.

The questionnaire was designed to have space for additional comments upon both the medical services in Rheindahlen and British Forces Germany in general.

In the 1996 survey, there were no specific questions regarding hospital services. However comments were frequently made. For this reason in 1997 two additional questions regarding which hospital services had been used, if any and the patient's overall satisfaction with the service that they had received were included (Appendix A). Similarly by the summer of 1997 , with the closure of the hospital, the physiotherapy and speech and language therapy departments were well established as being managerially part of the community services. They were therefore included within the second survey in order to get a complete view of the community disciplines.

In order to provide the maximum number of completed questionnaires for analysis, the forms were located in the main Reception, Community Nursing Reception and the main treatment room. The 1997 survey also included the physiotherapy and speech and language therapy departments at Wegberg - questionnaires were given to patients by the clerical staff. Patients were advised that the questionnaire was completely anonymous and that once completed should be deposited in one of the special "post boxes". The weeks chosen for the study were selected as being generally typical of normal staffing levels although in 1996 two of the three health visitors were absent. During the 1997 survey the Medical Centre was in the middle of a major refurbishment programme - as a consequence the main treatment room, dispensary and some of the community nurses offices were in temporary accommodation. It was recognised that working from the temporary accommodation may have an impact upon the satisfaction levels reported although almost certainly in the form of a "worst case" satisfaction level.

Completed questionnaires were collated and coded. For the core responses the following key was used - Very Satisfied $=4$, Satisfied $=3$, Dissatisfied $=2$, and Very Dissatisfied $=1$. It therefore follows that the average score indicates the greater level of overall satisfaction with a particular parameter. A four point Likert scale was used to prevent regression to the median. Statistical analysis was performed on Epi Info Version 5 (US Centers for Disease
Table 1

Total Patients Seen by Discipline during the Survey Weeks of 1996 and 1997

\begin{tabular}{|c|c|c|}
\hline & $\mathbf{1 9 9 6}$ & $\mathbf{1 9 9 7}$ \\
\hline Medical Officers & $\overline{975}$ & 816 \\
\hline Nurses & 468 & 318 \\
\hline Midwives & 18 & 16 \\
\hline Health Visitors & 88 & 196 \\
\hline $\begin{array}{c}\text { Physiotherapy } \\
\text { Speech \& Language } \\
\text { Therapy }\end{array}$ & Not tested & 60 \\
\hline $\begin{array}{c}\text { Community } \\
\text { Paediatrics }\end{array}$ & Not tested & 20 \\
\hline Chiropody & & \\
& 15 & Did not visit \\
& & $\mathbf{d u r i n g}$ week of \\
survey
\end{tabular}

Control Statistical Programme) on one of the personat Computers within the Practice.

\section{Results}

During the study period one thousand five hundred and sixty four patients were seen in 1996 and one thousand five hundred and thirty eight in 1997. Full details are given in Table 1. Excluded from the surveys were telephoges contacts, home visits or contacts with dispensary purely pick up a prescription. Excluded were also contacts wath the administrative parts of the Practice dealing w queries on patients' notes or other paperwork. Not includese in either survey were enquiries about hospital care co advice on medical grading as many of these are $8 \dot{8}$ telephone. It is unlikely that these patients differ in aty material way from those who completed the questionnatwe For simplicity, the methodology did not allow patients who had seen a nurse or health visitor first and then went on to see a doctor afterwards, or vice versa, to be counted once It is therefore possible that although the number o contacts is correct, some patients were counted more than once. The inflation of the above figures on the true numbe of patients seen is estimated to be no more than $5 \%$.

Table 2, gives the response rates by discipline for the two years. Given the poor response rates from patient

Table 2

Response Rates by Discipline

\begin{tabular}{|c|c|c|}
\hline & $\begin{array}{c}1996 \\
\text { Numbers }(\%)\end{array}$ & $\begin{array}{c}1997 \\
\text { Numbers (\%) }\end{array}$ \\
\hline Medical Officers & $294(30)$ & $166(20)$ \\
\hline Nurses & $43(6)$ & $42(13)$ \\
\hline Midwives & $3(18)$ & $2(13)$ \\
\hline Health Visitors & $2(2)$ & $8(4)$ \\
\hline Physiotherapy & Not tested & $77(68)$ \\
\hline $\begin{array}{c}\text { Speech \& Language } \\
\text { Therapy }\end{array}$ & Not tested & $9(15)$ \\
\hline Community & & \\
\hline Paediatrics & Not tested & 0 \\
\hline Chiropody & 0 & 0 \\
\hline Totals & $\mathbf{3 3 7}$ & $\mathbf{3 0 4}$ \\
\hline
\end{tabular}


who had seen the nursing professions, results have only been given for the whole practice.

In 1996 three hundred and thirty seven questionnaires were completed and were suitable for analysis as opposed to 296 in 1997. Eight patients in 1997 indicated that they had been seen by more than one professional and therefore they annotated the questionnaire as such. These scores were entered as separate patients.

The average age of patients seen was 28.7 years (SD 15.19 ) in 1996 and 28.0 yrs (SD 14.02) in 1997. The average reported waiting time to be seen by any professional both in and out of hours was 11.75 minutes (SD 13.97) in 1996 and 9.93 minutes (SD 12.11) in 1997.

The overall results for the two years are given in Tables 3 and 4 . The differences in satisfaction levels indicated for 1996 and 1997 for each parameter are not statistically significant.

The last two questions on the 1996 questionnaire were

Table 3

Overall results for patient satisfaction for all disciplines 1996 and 1997

\begin{tabular}{|c|c|c|c|c|}
\hline & 1996 & 1996 & 1997 & 1997 \\
\hline & $\begin{array}{l}\text { Mean } \\
\text { Score }\end{array}$ & $\begin{array}{c}\text { Standard } \\
\text { Deviation of } \\
\text { Mean }\end{array}$ & Mean Score & $\begin{array}{c}\text { Standard } \\
\text { Deviation of } \\
\text { Mean }\end{array}$ \\
\hline Reception & 3.71 & $0.4 \overline{6}$ & 3.67 & 0.49 \\
\hline Time given & 3.65 & 0.49 & 3.64 & 0.5 \\
\hline Explanation & 3.6 & 0.52 & 3.6 & 0.53 \\
\hline Attitude & 3.7 & 0.5 & 3.75 & 0.46 \\
\hline $\begin{array}{l}\text { Listened to } \\
\text { concerns }\end{array}$ & 3.64 & 0.52 & 3.71 & 0.48 \\
\hline $\begin{array}{l}\text { Service by } \\
\text { Dispensary }\end{array}$ & 3.53 & 0.55 & 3.43 & 0.51 \\
\hline $\begin{array}{c}\text { Overall } \\
\text { Satisfaction }\end{array}$ & 3.63 & 0.53 & 3.61 & 0.56 \\
\hline
\end{tabular}

Table 4

Overall Satisfaction rates for all disciplines for 1996 and 1997

\begin{tabular}{|c|c|c|c|c|}
\hline & $\mathbf{1 9 9 6}$ & $\mathbf{1 9 9 6}$ & $\mathbf{1 9 9 7}$ & $\mathbf{1 9 9 7}$ \\
\hline & $\begin{array}{c}\text { Percentage Very } \\
\text { Satisfied or } \\
\text { Satisfied }\end{array}$ & $\begin{array}{c}\text { Percent Very } \\
\text { Dissatisfied or } \\
\text { Dissatisfied }\end{array}$ & $\begin{array}{c}\text { Percentage Very } \\
\text { Satisfied or } \\
\text { Satisfied }\end{array}$ & $\begin{array}{c}\text { Percent Very } \\
\text { Dissatisfied } \\
\text { or Dissatisfied }\end{array}$ \\
\hline $\begin{array}{c}\text { Reception } \\
\text { Time given }\end{array}$ & 99.7 & 0.3 & 99.3 & 0.7 \\
\hline Explanation & 99.4 & 0.6 & 99.3 & 0.7 \\
\hline $\begin{array}{c}\text { Attitude } \\
\text { Listened to } \\
\text { concerns }\end{array}$ & 98.5 & 1.5 & 98.2 & 1.8 \\
\hline $\begin{array}{c}\text { Service by } \\
\text { Dispensary }\end{array}$ & 98.1 & 1.9 & 99.0 & 1.0 \\
\hline $\begin{array}{c}\text { Overall } \\
\text { Satisfaction }\end{array}$ & 98.5 & 1.7 & 99.2 & 1.1 \\
\hline
\end{tabular}

designed to elicit the view of patients on the RASU Medical Centre and upon the health services in British Forces Germany (BFG) in general. Many of the comments upon the Medical Centre were similar to the following:

"I have found the service I receive at the Med Centre second to none and have no suggestions for improvement - just keep up the good work"

or

"Very Satisfied, (the Medical Centre) has looked after the needs of my family very well"

Specific recommendations forthcoming in 1996 were that the Medical Centre look at car park provision, vaccinations being available at any time and that longer appointment times than the normal 10 minutes be more readily available. In 1997 the size of the Medical Centre car park was still an issue (the commonest comment), that the Medical Centre should revert from an all appointment system to having a sick parade, and that the waiting time to see the Practice nurse was too long. In addition some felt that we should not be asking for levels of satisfaction whilst various departments were located in temporary accommodation.

In 1996 the question regarding the overall service in $\mathrm{BFG}$ was also revealing. Some patients were obviously very happy:

\section{"In seventeen years in BFG we have received good service"}

The common theme, however, was of uncertainty and fear of using the German Hospital system. One hundredo and twenty one questionnaires had this part of the forn $\vec{P}-$ completed. Of these forty five had concerns about the use of Viersen and the closure of Wegberg. Commotg comments were:

"Worried about the language barrier for secondary care"

"Very concerned about future treatment with the closures of Wegberg"

"I hope the standard we are used to continues"

"I do not think that the new arrangements - Health Alliance and linked hospitals will work"

"There is a concern about the quality of the services in the future following the recent changes"

Given these considerable concerns, the 1997 questionnaire asked for information regarding the patients' experiences over the last year. Of the 304 completed forms, 152 were annotated as having used either Viersen or Dülken within the last year. Eighty one of these gave a description that allowed a department to be identified, 4 patients were unsure where they had been and 67 were either blank or a department could not be identified from the description. Of the 81 forms with an identifiable department. Casualty was indicated 20 times, Orthopaedics 8, Ear, Nose and Throat 3, Childrens' Ward 14, Surgical 8, Gynaecology 8, Maternity 15, Medical 1 and Neurosurgery 4.

The 1997 survey included one question in which the patient was asked to annotate on a four point Likert scale the level of overall satisfaction with the hospital services at

旁


Table 5

Patients overall satisfaction with the service provided at the hospital $(n=174)$

\begin{tabular}{|c|c|c|c|}
\hline Mean Score & $\begin{array}{c}\text { Standard Deviation } \\
\text { of the Mean }\end{array}$ & $\begin{array}{c}\text { Percentage Very } \\
\text { Satisfied or } \\
\text { Satisfied }\end{array}$ & $\begin{array}{c}\text { Percent Very } \\
\text { Dissatisfied or } \\
\text { Dissatisfied }\end{array}$ \\
\hline 3.24 & 0.84 & 84.5 & 16.5 \\
\hline
\end{tabular}

Viersen. It is interesting to note that of the 174 patients who filled in this part of the questionnaire, nearly $85 \%$ of patients were either satisfied or very satisfied with the treatment provided. (Table 5).

In comparison with the 1996 survey, the 1997 completed forms indicated less concern over the use of German hospitals, but there was still a minority with concern. Common themes were:

"A lot of work has been done by the Health Alliance...but the treatment of children does not measure up to English or Service hospitals"

"One would feel very isolated in a German hospital, if one did not speak German"

"More English speaking in hospital please"

"Language problems at hospital"

Some extremely favourable comments were also made:

"The care provided for my daughter was first class. The postoperative care and follow up left absolutely nothing to be desired"

"The Health Alliance has led to a vast improvement in services and is to be congratulated"

"I feel that the health services are excellent and compare very favourably with the UK"

\section{Discussion}

The British medical services West of the river Rhine have undergone unprecedented change over the last 12 months with the closure of RAF Hospital Wegberg and the transfer of in-patient services to German hospitals. The 1996 survey showed that the vast majority of patients who completed a questionnaire were happy with the service provided by the Rheindahlen Medical Centre. This situation continues in 1997, even through a major refurbishment programme, with several departments in temporary accommodation. These levels of satisfaction are higher than reported in the Medway Towns, most especially as younger patients tend to be less satisfied with the service they received (6). In Khayat and Salter's paper
$8.9 \%$ of patients aged between 17 and 44 were dissatisfied and $3.5 \%$ of those aged more than 45 years. Military practices normally expect a patient turnover of between 153 and $20 \%$ per annum. Given this turbulence of both patients $\underset{\Omega}{\Phi}$ and members of staff it is surprising that we found such $\Omega$ high levels of satisfaction given the fact that it has been? shown that the longer the doctor/patient relationship, theẹ. higher the satisfaction levels reported $(7,8)$.

The study's reliability is lowered by the relatively low response rate, especially for the Community Nursing Team? both in 1996 and 1997. On this basis, the figures need to $\overline{\bar{\omega}}$ be viewed with caution. However there is no suggestion $\bar{\sigma}$ that the views of those seeing a nurse are any differento from any other professional. The assessment of thes. General Practitioners in the Rhine Area is in keeping withthis study - that during 1996 the populace were extremely $\rightarrow$ concerned about the changes, most especially at Secondary $\vec{\omega}$ Care, but that this level of concern has subsided? considerably as the new service has been implemented. Attempts were made in the planning of the 1997 survey top. ensure that a greater representativeness was attained, but $\vec{f}$ obviously these attempts failed.

Of concern in 1997 is the minority of patients who weren dissatisfied with their care in a German hospital. The majoro issues still appear to be communication and anglicisationo of the service, albeit that in comparison with the $190^{6}$ survey the number and range of issues raised wiकtsc considerably less. Khayat and Salter from Swed reported similar levels of satisfaction with their hospiat ${ }^{\infty}$ care in a Casualty setting (3), whereas Campbell fromec West Lothian reported up to $32 \%$ dissatisfaction with service provided by a Casualty Department (9). None 5 flo these departments had to set up a new system, in a foreigh country, where the language of a significant number health care professionals was different from the population under study.

\section{Conclusion}

This study has shown that patients who attended the Medical Centre were almost universally satisfied with the्: service that was provided. It has confirmed that the majority of patients are happy with the new German Hospital System, but there is a minority who remained concerned over the changes.

\section{Acknowledgments}

I would like to thank all the staff of the Rheindahlen Medical Centre for their help in performing this study particularly the clerical staff who collated and coded theo questionnaires. 


\section{APPENDIX A \\ SATISFACTION QUESTIONNAIRE}

The medical services are always seeking to improve the standard of care that is provided. It would be of great value if you could spend a few moments filling out this confidential questionnaire so that we can get some feedback on the services provided. Please would you place the completed questionnaire in the post-box provided. The questionnaire is completely anonymous.

1. What day of the week is it?

2. How old are you, if the patient is a child, how old is he or she?

.years

3. Which health professional(s) are you seeing?

Doctor

Nurse

Midwife

..Physiotherapist

Speech Therapist

Health Visitor

4. How long did you have to wait before you were seen?

Minutes

5 . What time of the day were you seen? $\mathrm{am} / \mathrm{pm}$

Please ring the number which most closely shows how satisfied you were with the care you were given.

6. The service provided by Reception (if used)

7. The amount of time given to you by the doctor, nurse, health visitor, midwife, physio, speech therapist

8. The explanation of the problem

9. The attitude of the doctor, nurse, health visitor, midwife, physio, speech therapist

10. How well the doctor, nurse, health visitor, midwife, physio, speech therapist listened to your concerns.

11. The service provided by Dispensary (if used)

12. Your overall satisfaction with the service given to you

\section{Very Satisfied Satisfied Dissatisfied Very Dissatisfied}

4

4

4

4

4

4

4
3

3

3

3

2

2

2

2

2

3
1

1

1

1

13. Do you have any suggestions for the medical services in RASU.

14. Have you or a member of your family used either Viersen or Duilken Hospitals in the last year? Yes/No

15. If yes, which department(s) did you use

16. Please would you grade your overall satisfaction with the service provided at the hospital?

Very Satisfied Satisfied

4 3
Dissatisfied

Very Dissatisfied 2 1

17. Do you have any comments about the health services in BFG in general? 


\section{REFERENCES}

1. LeaCh AJ, WhitMore MK, Schofield J, Morris/G. Health Service Market Testing - the Experience of the Community Services Review Team in British Forces Germany. JR Army Med Corps. 1996; 142: 6770.

2. Everington P, LeACh AJ. Integrated Primary Care Led Care - A view of the future? In Richards J, ed. Conference Proceedings - Current Perspectives in Healthcare Computing 1996.

3. Hansagi H, CARlSSON B, Brismar B. The urgency of care need and patient satisfaction at a hospital emergency department. Health Care Management Review. 1992; 17(2): 71-75.

4. Gribien B. Satisfaction with access to general practitioner services in South Auckland, NZ Med J. 1993; 106: 360-362.
5. DiTommasso R, Willard M. The Development of aD Patient Satisfaction Questionnaire in the Ambulatory Setting. Fam Med. 1991; 23: 127-137.

6. Khayat K, Salter B. Patient satisfaction surveys as a⿳亠口冋 market research tool for general practitioners. $B r J G e n_{O}$ Pract. 1994; 44: 215-219.

7. HJORTDAHL P, LAERUM E. Continuity of care in generale practice: effect on patient satisfaction. Br Med J. 1992; 304: $1287-90$.

8. FREeman G, RICHARDS S. Is Personal continuity of care compatible with free choice of doctor? Patient's views을 on seeing the same doctor. Br J Gen Pract. 1993; 43: 493-497.

9. CAMPBell JL. General Practitioner Appointmentes. Systems. Patient Satisfaction and use of Accident andEmergency Services - a Study in one Geographical Area. Fam Pract. 1994; 11(4): 438-445. 